\title{
Genetically Engineered Plant Virus Resistance
}

\author{
Rebecca Grumet \\ Department of Horticulture, Michigan State University, East Lansing, MI 48824
}

Molecular genetic and plant transformation technologies have made it possible to use novel approaches to increase disease resistance in plants. This possibility is most clearly seen by the development of genetically engineered virus resistances; it is possible to use. cloned viral genes to confer resistance to infection by viruses. A major advantage of using viral genes, rather than host genes, is that potentially useful viral genes can be more easily identified, isolated, and cloned. Several recent examples of genetically engineered virus resistance in plants, as well as potential future approaches, will be described in this review.

Disease-resistant crop plants have long been produced by identifying resistant genotypes and then crossing individuals exhibiting resistance with cultivars that possess the requisite array of agriculturally valuable traits. Although highly successful in many cases, there can be limitations to classical plant breeding methods. The desired resistance is not always available, it mayonly exist in a species that is not interfertile with the crop, the genes for resistance may be tightly linked to undesirable traits, or the resistance may be multigenic and difficult to transfer (Knott and Dvorak, 1976; Roberts and Boothroyd, 1972; Wenzel, 1985).

Molecular genetic techniques may be used to overcome some of the factors limiting traditional plant breeding. One particular strength of these techniques is the potential to bypass fertility barriers among species. Not only have genes been transferred between different plant families, but the choice of genes is not even limited to the plant kingdom. Useful bacterial and viral genes have also been successfully transferred into plant species (e.g., Fraley et al., 1986; Comai et al., 1985). Additionally, once a gene of interest has been identified, the problem of tight linkage with undesirable traits can be avoided. The most challenging questions facing a molecular geneticist whose goals are crop improvement are: what are appropriate genes to transfer, and how can those genes be obtained?

These challenges are very real. The underlying mechanism of resistance is not known in the great majority of cases, and so there is no tag by which to identify and isolate the resistance genes. Furthermore, most plant species have very large genomes, a large

\footnotetext{
Received for publication 30 May 1989. Michigan State Univ. Agricultural Experiment Station Journal Article no. 13083. The cost of publishing this paper was defrayed in part by the payment of page charges. Under postal regulations, this paper therefore must be hereby marked advertisement solely to indicate this fact.
}

amount of repetitive DNA, and they are not very well-mapped (Meyerowitz and Pruitt, 1985).

An alternative approach 'to obtaining disease resistance genes is to use pathogen genes (Sanford and Johnston, 1985). This approach is based on the principle that in any given set of host-pathogen interactions, there are certain pathogen-encoded functions essential to the pathogen, but not to the host. If one of these pathogen-specific functions is disrupted (e.g., by expressing a pathogen gene at the wrong time, in the wrong amount, or in a counterfunctional form), the pathogenic process should be stopped. Two potential advantages of this approach over the use of host-derived resistance genes are: a) the source of resistance genes would not be in question as the genome of each pathogen would provide resistance genes, and b) since pathogens generally have smaller genomes and shorter life cycles than their hosts, the isolation of such genes should be simpler.

The possibility that viral genes could function as resistance genes has recently been demonstrated in a range of systems. Coleman et al. (1985) and Grumet et al. (1987) demonstrated for two model bacteriophage systems, SP and QB infection of Escherichia coli, that expression of antisense SP mRNAs or the negative regulatory protein, $\mathrm{QB}$ coat protein, confers resistance to the respective phage. This sort of resistance may even occur naturally in certain animal systems. Cells from a BALB/c mouse cell line containing the dominant $F v-4 r$ allele are protected from infection by murine leukemia virus (MuLV). This allele is a MuLV envelope glycoprotein gene that was incorporated into the host cell genome (Kozak et al., 1984). Similarly, White Leghorn chickens that were selected for resistance to Marek's disease (MD) showed an increase in the frequency of a gene that encodes the MD viral envelope protein (Kuhnlein et al., 1989). Furthermore, Salter and Crittenden (1989) demonstrated that introduction of the $A L V 6$ viral envelope gene of avian leucosis virus (ALV) into the germ line of chickens produced ALV-resistant chickens.

Genetically engineered virus resistance has also been demonstrated in several plant systems, and the list is growing rapidly. Hamilton (1985) discussed the use of plant viruses for disease control; at that time, the major emphasis was on cross-protection (i.e., the use of mild virus strains to protect against more severe strains). Although the possibility was discussed, genetically engineered virus resistance had not yet been demonstrated. Since then, a variety of examples have been reported using various approaches. Several groups demonstrated that expression of viral capsid genes by the host results in reduced susceptibility to virus infection. This result was first shown for tobacco mosaic virus in tobacco plants (Powell-Abel et al., 1986), and has since been demonstrated in field trials of transgenic tomato plants (Nelson et al., 1988). Coat protein genes have also been shown to inhibit infection by tobacco streak (Van Dun et al., 1988a) and 'tobacco rattle viruses (Van Dun and Bol, 1988), and cucumber mosaic virus (Cuozzo et al., 1988) in transgenic tobacco plants; alfalfa mosaic virus in transgenic tobacco and tomato plants (Loesch-Fries et al., 1987; Turner et al., 1987; Van Dun et al., 1987); and potato virus X in transgenic tobacco and potato plants (Hemenway et al., 1988; Hoekema et al., 1989). This method has often been termed genetically engineered cross protection (e.g., Powell-Abel et al., 1986; Turner et al., 1987), in reference to the hypothesis that the protection conferred by a mild virus strain against subsequent infection by a more severe strain is due to the presence of coat protein from the mild strain (Sherwood and Fulton, 1982).

Other approaches include the use of satellite sequences, antisense RNAs, and the whole genome of a mild virus strain. Transgenic tobacco plants expressing a complete mild strain of TMV were protected from infection by a challenging severe strain (Yamaya et al., 1988). Tobacco plants transformed with satellite sequences of cucumber mosaic virus (Harrison et al., 1987) or tobacco ringspot virus (Gerlach et al., 1987) were less susceptible to infection by their respective viruses. Transgenic tobacco plants expressing genes encoding viral antisense RNAs of cucumber mosaic virus (Cuozzo et al., 1988) or potato virus X (Hemenway et al., 1988) also had reduced rates of viral replication. In general, though, the level of resistance from antisense RNAs is not as high as the resistance conferred by coat proteins, mild virus strains, or satellite sequences. Each of these strategies will be described in turn. Finally, the possible use of defective interfering RNAs, sense RNAs, and pathogenesis-related proteins will be discussed.

\section{Viral coat protein genes}

Examples of resistance. The majority of examples of genetically engineered virus resistance in plants have used viral coat proteins (Table 1). Inoculated leaves of the transgenic plants show fewer chlorotic or necrotic lesions relative to control plants, and systemic spread of infection is either prevented, delayed, or reduced. Expression of the coat protein genes in these examples did 
Table 1. Examples of virus resistance conferred by viral coat protein genes.

\begin{tabular}{|c|c|c|c|c|c|c|c|}
\hline Virus & & Group & $\begin{array}{l}\text { Particle } \\
\text { shape }\end{array}$ & $\begin{array}{c}\text { Genome } \\
\text { organization }\end{array}$ & $\begin{array}{l}\text { Mode of } \\
\text { transmission }\end{array}$ & Host & Reference \\
\hline Tobacco mosaic virus & TMV & Tobamovirus & Rigid rod & Monopartite & Mechanical & $\begin{array}{l}\text { Tobacco } \\
\text { Tomato }\end{array}$ & $\begin{array}{l}\text { Powell-Abel et al., } 1986 \\
\text { Nelson et al., 1987, } 1988\end{array}$ \\
\hline \multirow[t]{2}{*}{ Alfalfa mosaic virus } & AIMV & $\begin{array}{l}\text { Alfalfa mosaic } \\
\text { virus group }\end{array}$ & Bacilliform & Tripartite & $\begin{array}{l}\text { Aphids (nonpersistent); } \\
\text { seed }\end{array}$ & Tobacco & Loesch-Fries et al., 1987 \\
\hline & & & & & & $\begin{array}{l}\text { Tobacco } \\
\text { Tomato } \\
\text { Tobacco }\end{array}$ & $\begin{array}{l}\text { Turner et al., } 1987 \\
\text { Turner et al.. } 1987 \\
\text { Van Dun et al,, } 1987\end{array}$ \\
\hline Potato virus $\mathrm{X}$ & PVX & Potexvirus & Flexous rod & Monopartite & Mechanical & $\begin{array}{l}\text { Tobacco } \\
\text { Potato }\end{array}$ & $\begin{array}{l}\text { Hemenway et al., } 1988 \\
\text { Hoekema et al., } 1989\end{array}$ \\
\hline Cucumber mosaic virus & CMV & Cucumovirus & Isometric & Tripartite & Aphids (nonpersistent) & Tobacco & Cuozzo et al., 1988 \\
\hline Tobacco rattle virus & TRV & Tobravirus & Rigid rod & Dipartite & Nematodes & Tobacco & Van Dun and Bol, 1988 \\
\hline Tobacco streak virus & TSV & Ilarvirus & Isometric & Tripartite & $\begin{array}{l}\text { Mechanical, } \\
\text { seed, pollen }\end{array}$ & Tobacco & Van Dun et al., 1988a \\
\hline
\end{tabular}

not have., any apparent negative effect on growth, fertility, or physical appearance of the plants. The resistance trait was stably transmitted over several generations.

The great majority of infectious plant viruses $(>76 \%$ ) are single-stranded, positivesense RNA viruses (Zaitlin and Hull, 1987). Although all of the viruses for which coat protein has been shown to confer resistance fall into that general category, they differ from each other for a variety of features, including: virus shape (rod-shaped vs. icosohedral); genome organization (monopartite vs. multipartite); mode of transmission (mechanical transmission, seed transmission, insect-vectored, nematode-vectored); and manner of encapsidation $\left(5^{\prime} \rightarrow 3^{\prime}\right.$ vs. $3^{\prime}$ $\left.\rightarrow 5^{\prime}\right)$. Thus the use of viral coat protein genes appears to be generally applicable. Undoubtedly the list of viruses and virus groups for which coat protein genes can confer disease resistance will continue to grow rapidly.

There are several necessary steps to produce transgenic plants that express viral coat protein genes. First, the viral RNA must be isolated and then used as a template for reverse transcription to produce a cDNA copy of all, or a portion of, the viral genome. Second, the viral coat protein gene must be identified, sequenced, and engineered into an expression vector with a transcriptional promoter that will allow the gene to be transcribed from DNA to messenger RNA. The cauliflower mosaic virus (CaMV) $35 \mathrm{~S}$ promoter was used most often in the studies reviewed here because it allows for highlevel constitutive (constant) expression of the gene(s) under its control. Third, the gene must have the necessary sequences to facilitate translation; e.g., for virus groups such as the potyviruses and comoviruses where the coat proteins are expressed as part of a larger polyprotein that is subsequently cleaved by viral-encoded proteases (Dougherty and Barrington, 1988; Vos et al., 1988) an AUG initiation codon must be added.

Once a gene that can be transcribed and translated has been assembled, it is transferred to a vector for introduction into the plant genome. The cases reported to date have used methods based on the leaf disk procedure for Agrobacterium tumefaciens-mediated transformation (Horsch et al., 1985; for review, see Fraley et al., 1986). Very briefly, A. tumefaciens is a natural genetic engineer; a normal part of its life cycle is to insert genes from its Ti plasmid into the host chromosomes. Engineered, disarmed strains of $A$. tumefaciens have been produced that allow the bacteria to introduce cloned genes of interest instead of the normal pathogenic genes. In the cases reviewed here, at least two genes would be introduced in tandem; an antibiotic resistance gene to use as a selectable marker, and the viral coat protein gene.

Explants of the host plant (e.g., leaf or cotyledon pieces) are exposed to the Agrobacterium. Cells that become transformed are selected by culturing on medium that contains antibiotic. Those cells that contain and express the antibiotic resistance gene should be able to survive and regenerate into new plants. Successful transformation is then verified by: a) testing for expression of the introduced gene by blot-hybridization and immunological blots (i. e., are the coat protein message and the coat protein itself being produced?), b) testing for incorporation of the gene into the host chromosomes by Southern blots, and c) by examining progeny generations for Mendelian inheritance of the new trait. This general outline for cloning genes, establishing expression, and introducing genes into plants is also relevant to the other strategies for virus resistance discussed later.

In several cases, the amount of protection observed was directly correlated to the amount of the coat protein present. Transgenic plants that had more than one copy of the coat protein gene incorporated into their genome were more resistant to infection than those with just one gene (Loesch-Fries et al., 1987). Similarly, different plants with the same number of genes, but greater levels of coat protein expression, were more protected (Hemenway et al., 1988; Hoekema et al., 1989). Levels of viral coat protein generally ranged from $\approx 0.01 \%$ to $0.2 \%$ total soluble plant protein, depending on the virus, the promoter, the number of genes incorporated, and the site of insertion in the host genome. Van Dun et al. (1988a) further showed that it was the coat protein molecule, and not the coat protein mRNA, that conferred resistance. Transgenic plants expressing the mRNA of an AIMV coat protein gene with a frame shift mutation were not protected against AlMV infection.

At this time, there have been very few field trials of genetically engineered virusresistant plants. The level of resistance observed in the field for transgenic, TMV-resistant tomatoes was as great, or greater, than that in the growth chamber or greenhouse (Nelson et al., 1988). Ninety-nine percent of virus-inoculated control 'VF36' tomato plants exhibited symptoms; fruit yield was reduced $25 \%$ to $35 \%$. Only $5 \%$ of the transgenic, coat protein-producing plants showed symptoms, and yield was not significantly affected. Thus, the resistance was clearly effective under field conditions. Furthermore, although there was an overall yield reduction in one transgenic line, a second, virus-resistant transgenic line yielded as well as the control 'VF36' under non-infected conditions, and significantly outyielded the control (by $35 \%$ to $40 \%$ ) when inoculated with virus. It was concluded that there was no negative effect of the coat protein gene per se on plant performance; the yield depression that was observed in one line was thought to be due to other aspects of transformation or regeneration (e.g., somaclonal variation).

Several of the studies demonstrated that coat protein-conferred protection could be extended to other strains of the virus or to related viruses. The coat protein of the U1 strain of TMV protected against infection by the severe PV 230 strain and the three strains of the related virus, tomato mosaic virus (Nelson et al., 1987, 1988); similarly, the coat protein of AIMV strain 425-Madison protected against AlMV strain McKinney (Loesch-Fries et al., 1987). The coat protein of tobacco rattle virus (TRV) protected against the related virus, pea early browning virus (PEBV) (van Dun and Bol, 1988). The coat proteins of TRV and PEBV show strong sequence homology (Angenent et al., 1986). Since there are many sets of viruses with homologous coat protein domains (e.g., potyviruses; Shukla and Ward, 1988), it may be possible that the ability of one coat protein gene to protect against more than one virus will occur in other cases.

Relationship to cross protection. The coat protein-conferred resistance has often been termed genetically engineered cross protection. Cross-protection is a well-known phenomenon whereby it is possible to protect against infection by a severe strain of virus by first inoculating with a mild strain (Fulton, 1986). There is evidence to suggest that 
it may be the presence of the coat protein from the first virus that interferes with early stages in the life cycle of the incoming, challenge virus (e.g., attachment, entry, uncoating). In support of the role of coat protein in cross protection is the observation that, $\mathrm{m}$ many cases, classical cross protection can be overcome by inoculating with viral RNA rather than whole virions (e.g., Sherwood and Fulton, 1982; Dodds et al., 1985). As with classical cross protection, several of the transgenic, virus-resistant plants that are protected against whole virions are susceptible to naked RNA (e.g., resistance to TMV, AIMV, and CMV is largely overcome by viral RNA).

Classical cross protection is currently used with several high-value horticultural crops such as citrus (for citrus tristeza virus), papaya (for papaya ringspot virus), and greenhouse tomatoes (for TMV) (Fulton, 1986). However, there are potential advantages to using genetically engineered plants rather than classical cross protection. First, prior inoculation of plants with a mild virus strain is labor-intensive. This method of protection is restricted to high-value crops with limited hectarage or population numbers. This would not be a problem with a genetically engineered crop. Second, when using classical cross protection, it is possible that the mild strain itself could cause adverse effects; that some combinations of the cross-protecting and severe strains could be detrimental; or the mild strain could mutate to a more severe strain. A single introduced gene, however, is unlike a whole virus. It is not capable of self-replication, multiplying to high levels, or spreading from plant to plant.

It should be noted that the mechanism of cross protection is not yet well-understood, and there is some evidence, using coat protein mutants and transencapsidated viruses, that coat protein is not necessarily involved (Zaitlin, 1976; Zinnen and Fulton, 1986). Cross protection has also been observed for viroids that do not have coat proteins (Niblett et al., 1978). On the other hand, not just any viral gene will confer virus resistance. Transgenic plants expressing the TMV 30$\mathrm{kDa}$ movement protein gene (Deem et al., 1987), or AIMV RNA 1 or RNA 2 genes (Van Dun et al., 1988b), are not protected against infection by TMV or AIMV, respectively.

Possible mechanisms of protection. Investigations using the transgenic TMV-resistant plant materials have indicated a possible mechanism for the coat protein in preventing infection. First, since coat protein/mediated protection was observed in protoplasts prepared from transgenic TMV coat protein-expressing. plants, as well as whole plants, it is not cell to cell movement or systemic spread that is prevented by the coat protein (or at least those processes are not the only ones affected) (Register and Beachy, 1988). There must be interference at the cellular level.

A current hypothesis for the uncoating of TMV, and possibly other viruses, is cotranslational disassembly (Wilson, 1984; Plaskitt et al., 1988; Wilson and Watkins, 1986). According to this model, host ribo- somes bind to the 5 ' end of the virion and actively uncoat the virus as they proceed to translate the genomic RNA. Treatment of whole TMV virions with $\mathrm{pH} 8$ buffer greatly increases the in vitro translatability of the virus. Since the virions still appear intact, and the RNA is still protected from ribonuclease degradation, the authors postulated that pH 8 treatment removes a very small number of coat protein subunits from the $5^{`}$ end of the rod.

The coat protein-conferred resistance was overcome if TMV particles were treated with $\mathrm{pH} 8$ buffer before inoculation of transgenic plants (Register and Beachy, 1988). The $\mathrm{pH}$ 8 treatment serves to make the virus more accessible to the ribosomes; hence, it was suggested that the coat protein in transgenic plants interferes with the virus life cycle by preventing uncoating of the virus. These data also suggest that neither reencapsidation nor stabilization of the virion are responsible for protection (Register and Beachy, 1988).

It should be noted, however, that although many groups have used capsid genes, the mechanism of resistance is not the same in each case. The various viruses tested all belonged to diverse virus groups with distinct biologies. Unlike the case for TMV described above, transgenic plants expressing the coat protein of potato virus X (PVX) are resistant to infections by both RNA and whole virions (Hemenway et al., 1988). One possible explanation for the difference between these two viruses lies in the difference in coating and uncoating mechanisms. TMV encapsidation begins near the $3^{6}$ end of the RNA and proceeds in both directions, predominantly 3' $\rightarrow$ 5' (Butler, 1984). In contrast, encapsidation of PVX most likely begins at the $5^{\circ}$ end of the RNA and proceeds in the $5^{\prime} \rightarrow 3^{\prime}$ direction (by analogy to the related papaya mosaic virus; Lok and Abouhaidar, 1986). A still different situation may exist for alfalfa mosaic virus (AIMV). There is evidence for AIMV that the coat protein may play a regulatory role in modulating viral replication (Houwing and Jaspars, 1986). Houwing and Jaspers (1986) showed that the addition of small amounts of AlMV coat protein to an in vitro transcription system had a strong inhibitory effect on viral minusstrand synthesis. However, since coat protein-conferred protection against AlMV was overcome by AlMV RNA (Loesch-Fries et al., 1987; Van Dun et al., 1987), interference with replication may not be as important in vivo. It is also possible that the coat protein interferes at more than one stage in the viral life cycle.

Interestingly, at least in one case, capability of the coat protein to interact with the viral RNA is not sufficient to confer resistance (Van Dun and Bol, 1988). There are two strains of TRV that have quite divergent coat proteins (39\% homologous). Although the coat proteins from the two strains are capable of encapsidating RNAs from the reciprocal strain, protection is only conferred against the homologous strain. Van Dun and Bol (1988) suggest that the inability to protect against the other virus may be due to reduced affinity for the RNA or an altered domain involved in a function other than RNA binding.

Another variable feature among the different virus resistances is dependence of the resistance on the level of viral inoculum. In classical cross protection, protection can be overcome by increasing the amount of inoculum. This was the case for transgenic plants expressing coat protein of TMV, AlMV, and PVX, but not CMV. Comparable CMV resistance (80\% to $90 \%$ fewer plants with symptoms) occurred at both moderate $\left(5 \mu \mathrm{g} \cdot \mathrm{ml}^{-1}\right)$ and high $\left(25 \mu \mathrm{g} \cdot \mathrm{ml}^{-1}\right)$ levels of inoculum (Cuozzo et al., 1988).

\section{Complete viral genomes}

Another approach to genetically engineering virus resistance was demonstrated by producing transgenic tobacco plants that express the complete genome of a mild, protective strain of TMV (Yamaya et al., 1988). Most of the transgenic plants grew as well as normal plants. They were either symptomless or showed a mild mosaic on the leaves. When challenged with a severe strain of TMV, the transgenic plants did not show severe symptoms and continued to grow normally. Unlike the work with the coat protein of TMV, inoculation with naked TMV RNA did not overcome the mild strain-conferred protection. In addition, the extent of protection was greater with the complete virus [protection against $5 \mu \mathrm{g} \cdot \mathrm{ml}^{-1} \mathrm{TMV}$ in transgenic mild strain-expressing tobacco vs. protection against 0.2 to $0.5 \mu \mathrm{g} \cdot \mathrm{ml}^{-1} \mathrm{TMV}$ with coat protein-expressing tobacco plants (Nelson et al., 1987; Powell-Abel et al., 1986)]. The higher level of protection in the whole virus system may have been due to the greater quantities of the mild virus than the coat protein alone (the virus replicates in the host), and/or due to differences in mechanism (the mild virus protected against naked RNA whereas coat protein did not).

Although the most appropriate comparison is between TMV infection of the transgenic mild virus-expressing and coat proteinexpressing plants, it should be noted that levels of protection observed in other coat proteinexpressing systems (e. g., PVX, CMV, AlMV), and for TMV in tomato, were as high as for the whole virus system described here. Whether this observation implies that using whole virus rather than coat protein in the other systems would provide even greater protection remains to be tested. Yamaya et al. (1988) point out disadvantages to the whole virus system: a) it is necessary to have a stable mild strain; b) the mild strain might cause a decrease in yield or quality of the crop; or c) the mild strain might mutate to a virulent strain. They suggest constructing deletion mutations to overcome these potential drawbacks. As was the case for conventional cross protection, the possible negative synergistic effect between the protecting strain, and the challenge strain, is also a potential problem.

\section{Antisense sequences}

A third possible approach for genetically engineering virus resistance is the use of an- 
tisense sequences. Antisense RNAs (RNAs that complement the messenger RNA strand) have been used in several microbial, animal, and plant systems to inhibit gene expression (e.g., Coleman et al., 1985; Green et al., 1986; Ecker and Davis, 1986). The mechanism by which antisense sequences inhibit expression is not clearly defined; however, several possibilities have been suggested (Ecker and Davis, 1986). For example, hybridization of the two complementary strands may limit access of the ribosomes to the mRNA, or the RNA-RNA hybrids may be selectively degraded. Since viral RNAs are not only mRNAs, they have several functions in the viral life cycle. It is thus possible that viral antisense sequences might interfere with the viral life cycle in other ways. In addition to inhibiting translation, viral antisense sequences might interfere with replication, or compete directly for specific viral or host proteins essential for replication (Cuozzo et al., 1988).

The capability of antisense sequences to inhibit viral replication was first demonstrated for bacteriophage SP infection of $E$. coli (Coleman et al., 1985). The use of antisense sequences has also been tested as a possible defense against infection by plant RNA viruses; $c D N A$ clones to various parts of viral genomes have been introduced into constructs that allow for transcription of the reverse strand, or antisense, RNA. Crum et al. (1988) used regions of the TMV genome encoding ribosome binding sites and were able to obtain up to $90 \%$ hybridization between viral genomic RNA and antisense RNAs in vitro. Duplex formation inhibited translation by $30 \%$ to $40 \%$. Sense fragments had no effect. Although not tested in this work, it would be interesting to determine the effect of these antisense sequences on the in vitro translation of $\mathrm{pH} 8$ treated virions do the antisense sequences. to the ribosome binding sites affect the cotranslational disassembly process described earlier?

The effect of antisense sequences was also tested in vivo. Rezian et al. (1988) used antisense fragments corresponding to the 5 ' untranslated regions of CMV RNA 1 and RNA 3 , and to the 3 ' end of CMV RNA 2. The $5^{6}$ ends are important in translation initiation and the' 3 ' end of the RNA has been implicated in the initiation of replication. Many transgenic tobacco plants expressing antisense sequences of the three different constructs were produced, but only the progeny of one individual showed resistance to CMV infection. Other plants expressing the same RNA at the same level were not resistant to infection. The authors concluded that it was probably not the antisense RNA that was responsible for resistance, but rather that some other unknown event (e.g., somaclonal variation) may have been involved.

Cuozzo et al. (1988) and Hemenway et al. (1988), working with CMV and PVX, respectively, bad limited success with the antisense approach. In these studies, the coat protein gene was introduced into tobacco plants in both the sense and antisense orientations, thereby facilitating direct comparison between the coat protein and antisense approaches. In both cases, the antisense-producing plants were more protected from infection than were control plants, but only at very low viral inoculum levels and only to a limited extent. For CMV, $70 \%$ to $100 \%$ protection was observed in coat protein-expressing plants when inoculated with virus concentrations of $25 \mu \mathrm{g} \cdot \mathrm{ml}^{-1}$. In contrast, the antisense-producing plants were only $50 \%$ protected when infected with $1 \mu \mathrm{g} \cdot \mathrm{ml}^{-1}$ virus (25-fold more dilute inoculum). Similar results were obtained with PVX. Plants expressing coat protein were $70 \%$ to $90 \%$ protected when inoculated with $5 \mu \mathrm{g} \cdot \mathrm{ml}^{-1}$ virus; antisense-producing plants were not markedly protected until the inoculum level was dropped 100-fold. Thus, it was possible to demonstrate that plants that express antisense RNAs were less susceptible to viral infection than were control plants, but the protection was observed only at very low inoculum levels.

\section{Satellite sequences}

Several groups of RNA viruses often have an associated small (generally 300 to 400 nucleotides), single-stranded RNA molecule called a satellite. Satellite RNAs have been viewed as parasites of the virus (Buzayan et al., 1986); they use viral replication machinery and coat themselves in viral coat protein, but do not share nucleotide sequences with the host virus and are not necessary for viral replication. Satellite RNAs can diminish the severity of symptoms that occur on virus-infected host plants and so investigators have tested the effect of introducing cloned satellite sequences into the host plant genome.

At least two examples have been published: Harrison et al. (1987) used the satellite sequence of CMV; Gerlach et al. (1987) used the satellite sequence of tobacco ringspot virus (ToRV). Several types of cDNA constructs were used. The most effective ones simulated the type of intermediates that occur in satellite RNA replication by using more than one copy of the satellite sequence. For CMV satellite, 1.3 or 2.3 unit length, head to tail concatemers (repeating units) were used. ToRV satellite concatemers of 3 unit lengths were capable of autocatylic cleavage in vitro (Buzayan et al., 1986) and in vivo (Gerlach et al., 1987) to form unit length RNAs. The satellite cDNA constructs were introduced into tobacco via A. tumefaciensmediated transformation as described earlier.

The presence of satellite sequences and the transcribed RNAs did not cause any symptoms or other abnormalities in growth, flowering, or seed production. Upon infection with the corresponding satellite-free virus, there was a large increase in the amount of satellite RNA, indicating that the virus was acting to replicate and process the satellite RNA.

Transgenic tobacco plants expressing CMV or ToRV satellite sequences exhibited fewer symptoms upon infection with their respective viruses than did control plants. Symptoms on the transgenic, satellite expressing plants resembled the symptoms that are pro- duced if the viral inoculum naturally contains satellite RNA. Satellite RNA supplied by the transgenic host plant could also be acquired by the infecting virus and carried along in subsequent inoculations made from infected sap of the transgenic plants. Symptoms caused by the viruses with newly acquired satellite RNAs were attenuated. The CMV satellite also reduced the symptoms caused by a closely related virus, tomato aspermy virus (TAV). There was no effect of satellite RNA on the disease caused by several other unrelated viruses (Harrison et al., 1987).

The effect of the satellites on viral replication was also studied. The titer of ToRV was reduced in transgenic plants expressing ToRV satellite sequences; similarly, CMV replication was greatly decreased $(80 \%$ to $95 \%$ ) in transgenic plants expressing CMV satellite. However, when transgenic plants with CMV satellite were infected with the related TAV, TAV replication was not affected, even though satellite synthesis was induced, symptoms were suppressed, and the satellite was carried along with the virus in subsequent inoculations (Harrison et al., 1987). Thus, the effect of the satellite in reducing symptom severity can be separated from the reduction of virus replication.

One of the advantages of using satellite sequences vs. coat protein genes for genetically engineering virus resistance is that the satellite sequences can become activated and amplified once an infection is initiated. For the coat protein to be effective, it is necessary to have constitutively high levels of the protein; as described earlier, the degree of resistance was, in many cases, correlated with the level of coat protein expression. Furthermore, it was possible in most cases to overcome resistance by increasing the inoculum concentration. With the satellite sequences, it is necessary to have only a low level of the satellite RNA transcript present; the satellite becomes replicated to high levels by the viral replication machinery of the infecting virus. As a result, the observed symptom suppression due to satellite RNA was not overcome by increasing viral inoculum rates.

However, there are some potential limitations and concerns to the use of satellite sequences. To begin, only a limited subset of plant viruses have naturally occurring, associated satellite sequences. Of even greater potential concern, however, is that the effect of satellites is not always predictable. In many cases, satellites make the symptoms less severe; in other cases they make them worse (e.g., Waterworth et al., 1979). The difference in effect on symptoms may be due to as little as a few nucleotide changes (Palukaitis, 1988), and since RNA replication machinery does not have the correction mechanisms that exist for DNA replication, the mutation rate for RNA viruses and associated types of RNA molecules tends to be very high (Horiuchi, 1975). In addition, the effect of a given satellite can vary with the particular virus strain with which it is associated. One possibility suggested by Harrison et al. (1987) is to disarm the satellite so 
that it is no longer capable of being transmitted from the transformed plant. This would help contain the problem, but the questions of interaction with the wrong strain and mutation while being amplified within the transgenic plant remain. Thus, although this approach has been very successful in the experiments reported to date, and these sorts of experiments can be very useful in helping to further our understanding of the biology of satellites, the use of this approach in the field may be more limited than for coat protein genes.

\section{Other approaches}

Other possible approaches have been suggested, or tested in vitro or in vivo. These include: interference with viral replication by sense RNAs, interference with viral replication by defective interfering particles, or the rise of transgenic plants that constitutively express pathogenesis-related proteins.

Sense RNAs. The use of specific sense RNAs has been suggested by Morch et al. (1987) and tested in vitro using the singlestranded RNA virus, turnip yellows mosaic virus (TYMV). The 3' region of RNA viruses is thought to be a recognition site for the viral replicase. cDNA fragments corresponding to the 3 ' terminal region of TYMV were used to produce small RNAs, or genome-like fragments, of the same strand as the viral genome. When added to an in vitro replication system, TYMV replication was greatly inhibited (50\% at equimolar levels of genome-like fragment and TYMV; $90 \%$ to $95 \%$ at 10 -fold excess of genome-like fragment). Other short RNAs that did not contain the viral 3' end did not inhibit replication. The suggested mechanism is competition between the genome-like fragment and the TYMV-RNA for binding to the replicase. It will be interesting to see the results of these sorts of experiments in vivo.

Defective interfering RNAs. Defective interfering RNAs (DI RNAs) are similar to satellite RNAs in that they are dependent on the helper virus for replication, use the helper virus coat protein, and can cause an attenuation of symptoms. In contrast to satellite RNAs, however, DI RNAs do share sequence homology to the helper virus; they are directly derived from the viral genome, but have discontinuities in the sequence. The first definitive report of the occurrence of a

Table 2. Demonstrated approaches for genetically engineering virus resistance

\begin{tabular}{|c|c|c|}
\hline Approach & Potential advantages & Potential disadvantages \\
\hline Coat protein & $\begin{array}{l}\text { Generally applicable } \\
\text { Reasonably effective }\end{array}$ & $\begin{array}{l}\text { Often dependent on level of coat } \\
\text { protein and viral inoculum }\end{array}$ \\
\hline Mild virus strains & $\begin{array}{l}\text { High-level protection } \\
\text { Self-amplifying }\end{array}$ & $\begin{array}{l}\text { May cause a decrease in yield or } \\
\text { quality } \\
\text { May mutate to virulent strain } \\
\text { May have a synergistic effect with } \\
\text { incoming virus }\end{array}$ \\
\hline Antisense & Generally applicable & Not very effective \\
\hline Satellite RNAs & $\begin{array}{l}\text { Amplified upon infection } \\
\text { High-level protection }\end{array}$ & $\begin{array}{l}\text { Limited to viruses with satellites } \\
\text { Effect of satellite is not always } \\
\text { predictable } \\
\text { Satellite may mutate and make } \\
\text { symptoms worse }\end{array}$ \\
\hline
\end{tabular}

DI RNA in association with a plant virus was by Hillman et al. (1987) for tomato bushy stunt virus (TBSV). The DIs were colinear deletion mutants of the helper virus genome. These molecules interfered with virus synthesis and reduced the severity of symptoms. DI RNAs are thought to interfere with the helper virus by competing for replication machinery. These properties make the use of existing DIs or the construction of new DI RNAs possible candidates for engineering resistance.

Expression of pathogenesis-related proteins. The use of pathogenesis-related (PR) proteins differs from all of the above examples in that the PR proteins are host-derived rather than viral-derived. PR proteins are a class of $\approx 10$ proteins that increase in many plant species in response to infection by a variety of pathogens (for review, see Van Loon, 1985). In one of the best-studied systems, the NN genotype of tobacco, the presence of PR proteins is correlated with TMV resistance. Recently, several of the PR proteins have been shown to be the hydrolytic cell wall-degrading enzymes chitinase and $\beta$-1 3-glucanase (Kauffman et al., 1987; Legrand et al., 1987). Thus, although correlated with virus resistance in at least one system, it is not clear how these particular enzymes might be involved in protecting against viruses. The function of several PR proteins, however, has not yet been defined. In a recent study by Linthorst et al. (1989), three different PR protein genes were individually introduced into tobacco under control of the constitutive CaMV 35S promoter. One was for a PR-1 protein of unknown function; another was for PR-S, which has been found to have sequence homology with a protemase inhibitor and an inhibitor of insect $\alpha$-amylase (Richardson et al., 1987); and the third, GRP, encodes a glycine-rich protein that may have a role in the cell wall (Van Kan et al., 1988). When challenged with TMV, however, these plants were not more resistant than were control plants. These experiments reiterate the difficulty in extrapolating from correlations between induced gene expression in response to pathogen attack, to establishing a specific function of those genes in disease resistance. This does not mean, however, that specific useful, host-derived virus resistance genes will not be identified in the future.

\section{SUMMARY}

One of the first demonstrations of the introduction of agriculturally useful traits via molecular genetic techniques is the production of genetically engineered virus-resistant plants. The use of viral genes as a source of resistance genes has greatly facilitated these efforts and the number of viruses for which engineered resistance has been demonstrated is growing rapidly. Several promising approaches have been demonstrated, each with different advantages and disadvantages $(\mathrm{Ta}$ ble 2); others remain to be tested. Although current examples of genetically engineered virus resistance have relied on the efficient transformation and regeneration systems available for members of the Solanaceae, the list of species that can be transformed and regenerated is growing rapidly [e.g., lettuce, celery, carrot, cauliflower, walnut, apple (Gasser and Fraley, 1989)]. Clearly, genetic engineering approaches hold strong potential for increasing virus resistance in horticultural crops in the near future.

\section{Literature Cited}

Angenent, G. C., H.J.M. Linthorst, A.F. van Belkun, B.J.C. Cornelissen, and J.F. Bol. 1986 RNA 2 of tobacco rattle virus strain TCM encodes an unexpected gene. Nucleic Acids Res. 14:4673-4683.

Butler, J.P.G. 1984. The current picture of the structure and assembly of tobacco mosaic virus. J. Gen. Virol. 65:253-279.

Buzayan, J. M., W.L. Gerlach, and G. Bruening. 1986. Non-enzymatic cleavage and ligation of RNAs complementary to a plant virus satellite RNA. Nature (London) 332:349-352.

Coleman, J., A. Hirashima, Y. Inokuchi, P.J. Green, and M. Inouye. 1985. A novel immune system against bacteriophage infection using complementary RNA (mic RNA). Nature (London) 315:601-603.

Comai, L., D. Facciotti, W. Hiatt, G. Thompson, R. Rose, and D. Stalker. 1985. Expression in plants of a mutant aroA gene from Salmonella typhimurium confers tolerance to glyphosate. Nature (London) 317:741-744.

Crum, C., J.D. Johnson, A. Nelson, and D. Roth. 1988; Complementary oligodeoxynucleotide mediated inhibition of tobacco mosaic virus RNA translation in vitro. Nucleic Acids Res. 16:45694581

Cuozzo, M., K.M. O'Connell, W. Kaniewski, R.X. Fang, N.-H. Chua, and N.E. Turner. 1988. Viral protection in transgenic tobacco plants expressing the cucumber mosaic virus coat protein or its antisense RNA. Biotechnology 6:549557.

Deem, C. M., M.J. Oliver, and R.N. Beachy. 1987. The 30-kilodalton gene product of tobacco mosaic virus potentates virus movement. Science 237:389-394.

Dodds, J. A., S.Q. Lee, and M. Tiffany. 1985. Cross protection between different strains of cucumber mosaic virus: effect of host and type of inoculum on accumulation of virions and double stranded RNA of the challenge strain. Virology 144:301-309.

Dougherty, W.G. and J.C. Barrington. 1988. Expression and function of potyviral gene products. Annu. Rev. Phytopathol. 26:123-143.

Ecker, J.R. and R.W. Davis. 1986. Inhibition of gene expression in plant cells by expression of antisense RNA. Proc. Natl. Acad. Sci. USA 83:5372-5376. 
Fraley, R.T., S.G. Rogera, and R.B. Horsch. 1986 Genetic transformation in higher plants. CRC Crit. Rev. Plant Sci. 4:1-46.

Fulton, R.W. 1986. Practices and precautions in the use of cross protection for plant virus disease control. Annu. Rev. Phytopathol. 24:6781.

Gasser, C.S. and R.T. Fraley. 1989. Genetically engineering plants for crop improvement. Science 244:1293-1299.

Gerlach, W. L., D. Llewellyn and J. Haseloff. 1987. Construction of a plant disease resistance gene from the satellite RNA of tobacco ringspot virus. Nature (London) 328:802-805.

Green, F. J., O. Prines, and M. Inouye. 1986. The role of antisense RNA in gene regulation. Annu. Rev. Biochem. 58:569-597.

Grumet, R., J.C. Sanford, and S.A. Johnston. 1987. Pathogen-derived resistance to viral infection using a negative regulatory molecule. Virology 161:561-569.

Hamilton, R.I. 1985. Using plant viruses for disease control. HortScience 20:848-852.

Harrison, B. D., M.A. Mayo, and D.C. Baulcombe. 1987. Virus resistance in transgenic plants that express cucumber mosaic virus satellite RNA. Nature (London) 328:799-802.

Hemenway, C., R.-X. Fang, W.K. Kaniewski, N.-H. Chua and N.E. Turner. 1988. Analysis. of the mechanism of protection in transgenic plants expressing the potato virus $\mathrm{X}$ coat protein or its antisense RNA, EMBO J. 7:1273-1280.

Hillman, B. I., J.C. Barrington, and T.J. Morris. 1987. A defective interfering RNA that contains a mosaic of a plant virus genome. Cell $51: 427-$ 433.

Hoekema, A., M.J. Huisman, L. Molendijk, P.J.M. Van Den Elzen, and B.J.C. Cornelissen. 1989. The genetic engineering of two commercial potato cultivars for resistance to potato virus X. Bio/Technology 7:273-278.

Horicuhi, K. 1975. Genetic studies of RNA phages, p. 29-50. In: N.D. Zinder (ed.). RNA phages. Cold Spring Harbor Laboratory, Cold Spring Harbor, N.Y

Horsch, R. B., J.E. Fry, N.L. Hoffman, D. Eicholtz. S.G. Rogers, and R.T. Fraley. 1985. A simple and general method for transferring genes into plants. Science 227:1229-1231.

Houwing, C.J. and E.M.J. Jaspars. 1986. Coat protein blocks the in vitro transcription of the virion RNAs of alfalfa mosaic virus. FEBS Lett. 209:284-288.

Kauffmann, S., M. Legrand, P. Geoffroy, and B. Fritig. 1987. Biological function of pathogenesis related proteins: four PR proteins of tobacco have 1,3- $\beta$-glucanase activity. EMBO J. 6:3209-3212

Knott, D.R. and J. Dvorak. 1976. Alien germplasm as a source of resistance to disease. Annu. Rev. Phytopathol. 14:211-235.

Kozak, C. A., N.J. Gromet, H. Ikeda, and C.E. Buckler. 1984. A unique sequence related to the ecotropic murine leukemia virus is associated with the Fv-4 resistance gene. Proc. Natl. Acad. Sci. USA 81:834--837.

Kuhnlein, U., J.S. Gavora, J.L. Spencer, D.E. Bernon, and M. Sabour. 1989. Incidence of endogenous viral genes in two strains of White Leghorn chickens selected for egg production and susceptibility or resistance to Marek's disease. Theor. Applied Genet. 77:26-32.

Legrand, M., S. Kauffmann, P. Geoffroy, and B. Fritig. 1987. Biological function of pathogenesis related proteins: four tobacco pathogenesis related proteins are chitinases. Proc; Natl. Acad. Sci. USA 84:6750-6754.
Linthorst, H. J. M., R.L.J. Meuwissen, S. Kauffmann, and J.F. Bol. 1989. Constitutive expression of pathogenesis-related proteins PR-1, GRP, and PR-S in tobacco has no effect on virus infection. Plant Cell 1:285-291

Loesch-Fries, L. S., D. Merle, T. Zinnen, L. Burhop, K. Hill, K. Krahn, N. Jarvis, S. Nelson, and E. Halk. 1987. Expression of alfalfa mosaic virus RNA 4 in transgenic plants confers virus resistance. EMBO J. 6: 1845-1851.

Lok, S. and M.G. Abouhaidar. 1986. The nucleotide sequence of the 5 ' end of papaya mosaic virus RNA: Site of in vitro assembly initiation. Virology 153:289-296.

Meyerowitz, E.M. and R.E. Pruitt. 1985. Arabidopsis thaliana and plant molecular genetics. Science 229:1214-1218.

Morch, M. D., R.L. Joshi, T.M. Denial, and A.L. Haenni. 1987. A new sense approach to block viral RNA replication in vitro. Nucleic Acids Res. 15:4123-4130.

Nelson, R. S., P. Powell Abel, and R.N. Beachy. 1987. Lesions and virus accumulation in inoculated transgenic tobacco plants expressing the coat protein gene of tobacco mosaic virus. $\mathrm{Vi}$ rology 158:126-132.

Nelson. R. S.. S.M. McCormick, X. Delaney, P. Dube, J. Layton, E.J. Anderson, M. Kaniewska, R.K. Proksch, R.B. Horsch, S.G. Rogers, R.T. Fraley, and R.N. Beachy. 1988. Virus tolerance, plant growth, and field performance of transgenic tomato plants expressing coat protein from tobacco mosaic virus. Biotechnology 6:403-409.

Niblett, C. L., E. Dickson, K.H. Fernow, R.K. Horst, and M. Zaitlin. 1978. Cross protection among four viroids. Virology 91: 198-203.

Palukaitis, P. 1988. Pathogenicity regulation by satellite RNAs of cucumber mosaic virus: minor nucleotide sequence changes alter host responses. Mol. Plant Microbe Interactions 1:171181.

Plaskitt, K. A., P.A.C. Watkins, D.E. Sleat, D.R. Gallie, J.G. Shaw, and T.M.A. Wilson. 1988 Immunogold labelling locates the site of disassembly and transient gene expression of tobacco mosaic virus-like pseudovirus particles in vivo. Mol. Plant Microbe Interactions 1:10-16.

Powell-Abel, P., R.S. Nelson, B. De, N. Hoffmann, S.G. Rogers, R.T. Fraley, and R.N Beachy. 1986. Delay of disease development in transgenic plants that express the tobacco mosaic virus coat protein gene. Science 232:738 743.

Register, J.C. and R.N. Beachy. 1988. Resistance to TMV in transgenic plants results from interference with an early event in infection. Virology 166:524-532.

Rezian. M. A.. K.G.M. Skene, and J.G. Ellis. 1988. Anti-sense RNAs of cucumber mosaic virus in transgenic plants assessed for control of the virus. Plant Mol. Biol. 11:463-471.

Richardson, M., S. Valdez-Rodriguez, and A. Blanco-Labra. 1987. A possible function for thaumatin and a TMV-induced protein suggested by homology to a maize inhibitor. Nature (London) 327:432-434.

Roberts, D.A. and C.W. Boothroyd. 1972. Fundamentals of plant pathology. W.H. Freeman, San Francisco.

Salter, D.W. and L.B. Crittenden. 1989. Artificial insertion of a dominant gene for resistance to avian leukosis virus into the germ line of the chicken. Theor. Applied Genet. 77:457-461.

Sanford, J.C. and S.A. Johnston. 1985. The concept of parasite derived resistance- Deriving resistance genes from the parasite's own gen- ome. J. Theor. Biol. 113:395-405.

Sherwood, J.L. and R.W. Fulton. 1982. The specific involvement of coat protein in tobacco mosaic virus cross protection. Virology 119:150158.

Shukla, D.D. and C.W. Ward. 1988. Amino acid sequence homology of coat proteins as a basis for identification" and classification of the potyvirus group. J. Gen. Virol. 69:2703-2710.

Turner, N. E., K.M. O'Connell, R.S. Nelson, P.R. Sanders, R.N. Beachy, R.T. Fraley, and D.M. Shah. 1987. Expression of alfalfa mosaic virus coat protein gene confers cross-protection in transgenic tobacco and tomato plants. EMBO J. 6:1181-1188.

Van Dun, C.M.P. and J.F. Bol. 1988. Transgenic tobacco plants accumulating tobacco rattle virus coat protein resist infection with tobacco rattle virus and pea early browning virus. Virology 167:649-652.

Van-Dun, C. M. P., J.F. Bol, and L. Van VlotenDoting. 1987. Expression of alfalfa mosaic virus and tobacco rattle virus coat protein genes in transgenic tobacco plants. Virology 159:299305

Van Dun, C. M. P., B. Overduin, L. Van VlotenDoting, and J.F. Bol. 1988a. Transgenic tobacco expressing tobacco streak virus or mutated alfalfa mosaic virus coat protein does not cross protect against alfalfa mosaic virus infection. Virology 164:383-389.

Van Dun, C. M. P., L. Van Vloten-Doting, and J.F. Bol. 1988b. Expression of alfalfa mosaic virus cDNA 1 and 2 in transgenic tobacco plants. Virology 163:572-578.

Van Kan, J. A. L., D.J.C. Cornelissen, and J.F. Bol. 1988. A virus inducible tobacco gene encoding a glycine-rich protein shares putative regulatory elements with the ribulose bisphosphate carboxylase small subunit gene. Mol. Plant Microbe Interactions 1:107-112.

Van Loon, L.C. 1985. Pathogenesis related proteins. Plant Mol. Biol. 4:111-116.

Vos, P.J. Verver, M. Jaegle, J. Wellink, A. Van Kammen, and R. Goldbach. 1988. Two viral proteins involved in the proteolytic processing of the cowpea mosaic virus polyprotein. $\mathrm{Nu}-$ cleic Acids Res. 16:1967-1985.

Waterworth, H. E., J.M. Kaper, and M.E. Tousignant. 1979. CARNA 5, the small cucumber mosaic virus-dependent replicating RNA, regulates disease expression. Science 204:845-847.

Wenzel, G. 1985. Strategies in unconventional breeding for disease resistance. Annu. Rev. Phytopathol. 23:149-172.

Wilson, T.M.A. 1984. Cotranslational disassembly of tobacco mosaic virus in vitro. Virology 137:255-265.

Wilson, T.M.A. and P.A.C. Watkins. 1986. Influence of exogenous viral coat protein on the cotranslational disassembly of tobacco mosaic virus particles in vitro. Virology 149: 132-135.

Yamaya, J., M. Yoshioka, T. Meshi, Y. Okada, and T. Ohno. 1988. Cross protection in transgenic tobacco plants expressing a mild strain of tobacco mosaic virus. Mol. Gen. Genet. 315:173-175.

Zaitlin, M. 1976. Viral cross protection: more understanding is needed. Phytopathology 66:382383.

Zaitlin, M. and R. Hull. 1987. Plant virus-host interactions. Annu. Rev. Plant Physiol. 38:291315.

Zinnen, T.M. and R.W. Fulton. 1986. Cross protection between sunhemp mosaic and tobacco mosaic viruses. J. Gen Virol. 67: 1679-1687. 